\begin{tabular}{l|l}
\hline ISTEMA \\
ELETONNICO \\
DE REVISTAS \\
SER I UFPR
\end{tabular}

\title{
As universidades e a formação ambiental na América Latina*
}

\author{
Enrique LEFF ${ }^{1}$
}

${ }^{1}$ Coordenador da Rede de Formação Ambiental para a América Latina e o Caribe, Programa das Nações Unidas para o Meio Ambiente.

\section{A educação ambiental no nível superior na América Latina}

A Conferência das Nações Unidas sobre o Meio e Ambiente Humano, realizada em Estocolmo em 1972, chamou a atenção mundial sobre a crise ambiental gerada por uma racionalidade econômica incapaz de valorizar os recursos e serviços ecológicos da natureza que constituem a base de sustentabilidade da produção. A partir desse momento, tornou-se manifesta a alarmante destruição ecológica provocada pelos processos produtivos, os padrões tecnológicos e as práticas de consumo, guiados pela tendência a maximizar o benefício e os excedentes econômicos a curto prazo. Esta lógica foi desmatando e erosionando as terras do planeta, contaminando o ar, a água, os solos e os mares, bem como degradando a qualidade de vida do gênero humano.

A partir desse momento, discutiu -se a necessidade de reorientar os estilos de desenvolvimento e as práticas produtivas para torná-los ecologica- mente sustentáveis, economicamente suportáveis e socialmente equitativos. Isso exigia uma mudança nos valores que normatizam o comportamento dos agentes econômicos e da sociedade em seu conjunto, bem como a transformação do conhecimento e a inovação de tecnologias para resolver os problemas ambientais. A sensibilização da sociedade, a incorporação da dimensão ambiental no sistema educativo e a formação de recursos humanos de alto nível foram colocadas como princípios fundamentais para construir uma nova ordem social.

Seguindo essas iniciativas, em 1975 foi criado o Programa Internacional de Educação Ambiental (Pnuma/Unesco). A Conferência Mundial sobre Educação Ambiental, celebrada em 1977 em Tbilisi, estabeleceu as grandes orientações para incorporar a "dimensão ambiental" a partir de uma perspectiva interdisciplinar em todo sistema educativo, desde a educação informal e os níveis de instrução básica até a formação universitária (Unesco, 1980). Esses princípios foram ratificados na Conferência Mundial sobre Educação e Formação Ambiental Unesco/

\footnotetext{
*Tradução para o português de Terumi Koto Bonnet Villalba, professora do Departamento de Letras Estrangeiras Modernas da UFPR. A versão original deste texto foi apresentada na Conferência Novos Papéis da Educação Superior, organizada por Unesco/Cresalc, realizada em Caracas nos dias 2 e 3 de maio de 1991. Republicado de Cadernos de Desenvolvimento e Meio Ambiente, n. 2, 1995, p. 11-31.
} 
Pnuma (Moscou, 1987), e mais recentemente pelo Programa 21, assinado pelos chefes de Estado de todo orbe na Conferência das Nações Unidas sobre Meio Ambiente e Desenvolvimento, realizada no Rio de Janeiro em 1992.

Na América Latina e no Caribe as próprias instituições de pesquisa e educação contribuíram, desde o início, para esses debates, com uma reflexão própria sobre a problemática ambiental do desenvolvimento, dando impulso a um processo de formação ambiental. Já em 1976, a Associação Mexicana de Epistemologia e a Universidade $\mathrm{Na}$ cional Autônoma do México (Unam) organizaram o Primeiro Simpósio sobre Ecodesenvolvimento (Leff, 1977), no qual discutiu-se a contribuição das diferentes disciplinas científicas para as práticas de ecodesenvolvimento. Alguns anos mais tarde, foi realizado o projeto coletivo de pesquisa sobre $A$ articulação das ciências para a gestão ambiental, auspiciado pelo Centro Internacional de Formação em Ciências Ambientais. Nele, um grupo de pesquisadores ibero-americanos desenvolveu os princípios da interdisciplinaridade no campo do saber ambiental, analisando a incorporação da dimensão ambiental aos diferentes paradigmas do conhecimento e apresentando diferentes enfoques metodológicos ao estudo do manejo integrado, sustentável e suportável de recursos. (Leff et al., 1986).

Os governos da região também promoveram um processo de educação e formação ambiental. Assim, em 1977, levaram ao Conselho de Administração do Pnuma a necessidade de criar uma rede de instituições de formação ambiental na América Latina e no Caribe, para potencializar a formação de profissionais de alto nível, capazes de instrumentalizar as políticas ambientais da região. Deste modo, em 1982, foi iniciado o Programa Geral da Rede de Formação Ambiental para a América Latina e o Caribe, baseado na cooperação dos países da região, com o apoio do Pnuma. Com isso gerou-se um amplo processo para a formação de recursos humanos a partir de uma perspectiva própria da região, e fomentou-se o desenvolvimento de programas de formação profissional através da reorganização de cursos e o fortalecimento de centros de excelência em diversos países da região.

Em outubro de 1985, foi celebrado em Bogotá, nos moldes do Programa Internacional de Educação Ambiental (Unesco/Pnuma) e da Rede de Formação Ambiental, o Primeiro Seminário sobre Universidade e Meio Ambiente na América Latina e no Caribe, do qual participaram mais de 200 universidades da região, quando foram analisadas tanto a problemática como a configuração da introdução da dimensão ambiental no campo das ciências naturais, sociais, tecnológicas e da saúde (Pnuma/ Unesco, 1988). O seminário recomendou um plano de ação para impulsionar a educação ambiental nas universidades da região, com uma coordenação interuniversitária e o apoio dos organismos internacionais, principalmente da Unesco e do Pnuma. Destacou-se a necessidade de impulsionar o saber ambiental das ciências sociais que apareciam como aquelas que tinham se mostrado menos sensíveis à problemática ambiental, bem como de criar centros interdisciplinares de formação e pesquisa ambiental nas universidades, estabelecendo vínculos com a comunidade.

Seguindo essas recomendações, o Centro de Pesquisas Interdisciplinares em Humanidades da Unam do México, com o patrocínio da Unesco e em cooperação com a Rede de Formação Ambiental do Pnuma, empreendeu um projeto de pesquisa sobre As ciências sociais e a formação ambiental a nível universitário. Nesse projeto foram analisadas as contribuições de diferentes disciplinas e campos temáticos das ciências sociais (sociologia, economia, antropologia, direito, ecologia e geografia 
humanas, estudos urbanos e análise de sistemas complexos) para a análise integrada dos problemas socioambientais; ao mesmo tempo, foram discutidos os processos de incorporação do saber ambiental aos paradigmas das ciências sociais e sugeridos os enfoques e ações para a formação ambiental no campo das ciências sociais. (Leff et al., 1994).

O Seminário de Universidade e Meio Ambiente de Bogotá, em 1985, impulsionou um importante processo de formação ambiental nas universidades da região, o que levou ao estabelecimento de centros, núcleos, estudos e institutos de pesquisa que estão desenvolvendo programas ambientais em diversas universidades. Da mesma forma, foram criadas associações e consórcios de universidades que estão elaborando programas conjuntos de pesquisa, intercâmbio acadêmico e de informação, e complementação curricular. Um exemplo disso é a criação da Associação de Universidades do Grupo Montevidéu (que congrega 12 universidades da Argentina, Brasil, Paraguai e Uruguai) e a constituição de um Comitê de Meio Ambiente. Do mesmo modo, a Rede de Formação Ambiental constituiu, dentro dos moldes do Programa Regional Interagencial, consórcios de instituições que trabalham no campo da saúde ambiental a gestão ambiental urbana, a educação ambiental em nível universitário, a biodiversidade e a agrossilvicultura, a desertificação e o desenvolvimento sustentável. Como resultado disso, configurou-se um Sistema de Pós-Graduações em Meio Ambiente e Desenvolvimento Sustentável que integra mais de 50 cursos de especialização, mestrado e doutorado em diversas temáticas.

Não obstante esses avanços, o desenvolvimento de programas de pesquisa e de formação ambien- tais na região é lento. Nele se conjugam diversas causas, desde os obstáculos epistemológicos com os quais se depara a constituição de novos paradigmas ambientais até as barreiras institucionais e os interesses disciplinares em que se desenvolvem as práticas acadêmicas. A crise econômica que a região sofreu durante os anos 80 e a presente década, e que coincidiu com as primeiras etapas de promoção da educação ambiental, afetou o ritmo do avanço desse processo. Esse estado de emergência e sobrevivência acadêmica inibiu os incentivos, as capacidades e o tempo de trabalho intelectual necessário para gerar iniciativas capazes de transformar o conhecimento, impulsionar projetos de pesquisa e elaborar os conteúdos e métodos de programas de formação ambiental.

Os organismos internacionais do Sistema das Nações Unidas não dispunham de recursos suficientes para apoiar projetos específicos e induzir um processo mais amplo de formação ambiental nas universidades. Por outra parte, as instituições de financiamento não tiveram a vontade de apoiar o avanço da formação ambiental em nível profissional. Isso se deve em parte ao caráter não produtivo e não retornável desses “empréstimos”, mas também ao contrassenso dos bancos em investir recursos numa formação ambiental crítica da racionalidade econômica dominante ${ }^{1}$.

A Conferência das Nações Unidas sobre Meio Ambiente e Desenvolvimento, realizada no Rio de Janeiro em 1992, deu um novo impulso ao desenvolvimento de programas de formação nas universidades ao reiterar a importância da crise ambiental. Atualmente é possível identificar mais de 200 cursos regulares de pós-graduação na região,

\footnotetext{
${ }^{1}$ Neste sentido, um ambicioso programa regional de capacitação ambiental foi formulado em 1989 e impulsionado pelo próprio presidente do BID, não tendo sido aprovado pelo Conselho Diretivo do banco. Esse projeto contemplava o fortalecimento de diversos centros de excelência na região para prover cursos regionais de capacitação e formação em diferentes áreas ambientais críticas.
} 
ofertados por mais de 130 instituições, sobre temas relacionados com o meio ambiente e o desenvolvimento sustentável. A maioria desses programas é nova ou foi atualizada após 1992. Certamente entre esses também se encontram programas da moda, que não só incorporaram os termos "sustentável" ou "suportável" a seus currículos tradicionais, mas cujo caráter e conteúdos ambientais não foram reformulados para incorporar a dimensão ambiental do desenvolvimento.

Não obstante os avanços anteriores, o caráter ambiental e interdisciplinar desses centros de formação e pesquisa ambiental ainda é incipiente. A maioria de seus programas se encontra em processo de amadurecimento e sua consolidação deve passar pela formação de pesquisadores e de pessoal docente para formar verdadeiras equipes interdisciplinares. Em muitos casos, as estruturas e os conteúdos curriculares dos cursos que são ofertados não foram transformados, nem se conseguiu canalizar recursos suficientes para gerar centros e programas estáveis de pesquisa e de formação ambientais. Alcançar esses objetivos supõe enormes desafios teóricos, acadêmicos e institucionais para o avanço da formação ambiental. No entanto, uma condição para isso é o reconhecimento do valor que têm a produção de conhecimentos e a formação de recursos humanos para poder resolver os problemas ambientais do mundo atual e poder transitar em direção a uma nova racionalidade social, fundada nos princípios da sustentabilidade ecológica, da equidade social e da diversidade cultural.

Contra isso se opõe uma cultura neoliberal acrítica que leva à desvalorização do saber ambiental diante dos imperativos da mudança global. As instituições educativas e a universidade pública enfrentam uma crise financeira e políticas econômicas que reduzem o valor da educação, a produção de conhecimento e a formação de recursos humanos ao valor de mercado. A capitalização da natureza implica a capitalização do saber. Tudo isso obstaculiza a transformação do conhecimento e das instituições educacionais para incorporar a dimensão ambiental na formação de recursos humanos capazes de compreender e resolver os complexos problemas socioambientais do nosso tempo.

Esses processos de valorização - que fazem parte das mudanças globais - estão afetando os critérios de tomada de decisões, tanto dos organismos nacionais como dos internacionais relacionados com a promoção e o apoio à formação ambiental, ao procurar dar um sentido mais administrativo e formal à gestão ambiental. Dessa forma, a educação e a formação ambientais, concebidas na Conferência Mundial sobre Educação Ambiental de Tbilisi, em 1977, como um processo de construção interdisciplinar do saber e de novos métodos holísticos para apreender a complexidade dos processos socioambientais emergentes na mudança global, estão sendo reduzidas a "componentes" de capacitação.

Desde a constituição do Programa Internacional de Educação Ambiental em 1975, o Pnuma exerceu um papel fundamental no desenvolvimento da capacitação e da formação ambiental em nível mundial. A Agenda 21, emanada da Conferência das Nações Unidas para o Meio Ambiente e Desenvolvimento em 1992, referendou a importância da educação e da formação ambiental. No entanto, o Conselho de Administração do Pnuma, formado pelos titulares das agências nacionais do meio ambiente de todos os países, na $18^{\mathrm{a}}$ sessão realizada em Nairobi, em maio de 1995, praticamente dissolveu o programa global de educação e formação ambiental do Pnuma ao eliminar os recursos desse projeto.

Contrariamente a essa decisão, na IX Reunião Ministerial sobre Meio Ambiente da América Latina e do Caribe, celebrada em Havana, Cuba, em setembro de 1995, os governos da região decidiram 
continuar dando a mais alta prioridade ao programa de formação ambiental do Pnuma para consolidar um sistema regional de pós-graduações em meio ambiente e promover a capacitação ambiental em nível comunitário. Isso supõe a necessidade de legitimar a importância fundamental que representa a formação de recursos humanos para incrementar as capacidades dos países da América Latina e do mundo inteiro para implementar políticas eficazes de proteção ambiental e de desenvolvimento sustentável.

\section{O saber ambiental e a transformação do conhecimento}

A emergência do saber ambiental implica em transformações do conhecimento que vão além da incorporação de componentes ou conteúdos ecológicos para adaptar os cursos tradicionais às exigências do desenvolvimento sustentável. A problemática ambiental emerge como um questionamento social à racionalidade econômica dominante, cujos efeitos sobre a destruição das condições ecológicas da produção, o incremento da pobreza e a degradação da qualidade de vida das maiorias alcança dimensões planetárias. A questão ambiental é, pois, uma problemática social que extrapola o âmbito das universidades, a reciclagem de profissionais e a refuncionalização da educação superior, para adaptar-se às novas demandas de uma modernidade capaz de preservar o ambiente e de manter um equilíbrio entre crescimento econômico e conservação ecológica.

Não é possível analisar os processos socioambientais gerados por essa crise, nem reverter suas tendências sem transformar os conhecimentos, valores e comportamentos que configuram a racionalidade social atual. Nesse sentido, é necessário passar da consciência social sobre os problemas ambientais à criação de novos conhecimentos e métodos na formação profissional, o que constitui um dos desafios mais importantes para a educação superior na última década do século.

O saber ambiental não é um novo setor do conhecimento ou uma nova disciplina. A formação ambiental não se reduz à incorporação de uma matéria adicional de ecologia aos conteúdos curriculares atuais. Mais do que uma dimensão, trata-se de um saber emergente que perpassa todas as disciplinas e todos os níveis do sistema educativo.

Da perspectiva da história do conhecimento, o meio foi se configurando como um sistema de relações que circunda os objetos de conhecimento centrados em processos materiais específicos: biológicos, econômicos, culturais. No entanto, o privilégio que a teoria de sistemas outorgou à análise das relações estruturais entre diversos processos socioambientais, sobre a construção crítica do conhecimento, levou a dissolver o núcleo de racionalidade das ciências centradas em seus objetos de conhecimento para apreender os diversos domínios de materialidade do real: a ordem física, vital, simbólica, histórica e inconsciente.

Como observa Canguilhem, "o meio torna-se um instrumento universal de dissolução das sínteses orgânicas individuais no anonimato dos elementos e os movimentos universais. O meio (aparece) puramente como um sistema de relações sem suportes" (Canguilhem, 1971: 134).

O meio não se torna objeto de nenhuma ciência, nem é o campo de articulação das ciências centradas em objetos de conhecimento que dão conta de processos materiais específicos. O ambiente aparece como uma problemática social generalizada, marcada pela degradação do meio físico, do equilíbrio ecológico e da qualidade de vida, que problematiza os paradigmas das ciências para internalizar um saber ambiental emergente que se constitui na 
interfase entre o natural e o social. Da perspectiva sociológica, o ambiente é o espaço físico e social dominado e excluído pelos efeitos da racionalidade econômica dominante: a natureza explorada como um campo de externalidade da economia, a perda de diversidade biológica e cultural, a pobreza associada à destruição do patrimônio de recursos dos povos e a dissolução de suas identidades étnicas. Assim, o ambiente não é o meio que circunda as espécies e as povoações biológicas. É uma categoria sociológica (e não biológica) relativa a uma racionalidade social configurada por um sistema de valores, saberes e comportamentos.

A compreensão e a ação sobre a questão ambiental requerem um enfoque holístico e uma abordagem epistemológica que permitam apreender a convergência de diferentes processos (ecológicos, produtivos, tecnológicos, culturais, econômicos e políticos), requerendo assim a articulação de diferentes saberes, ciências e disciplinas. (Leff, 1994a, cap. 2).

O saber ambiental emerge dessa problemática como um campo de externalidade dos paradigmas constituídos do conhecimento. Esse saber está em processo de construção; não é um conhecimento acabado, sistematizado e axiomatizado, integrável aos conteúdos curriculares de novos cursos ou carreiras. O saber ambiental tampouco constitui uma dimensão neutra e homogênea para ser assimilada pelos paradigmas atuais de conhecimento. Pelo contrário, o saber ambiental emerge de uma razão crítica, configurando-se em contextos ecológicos e socioculturais específicos, problematizando os paradigmas institucionalizados do conhecimento. É um saber que vai se destacando em relação ao objeto e ao campo temático de cada ciência, questionando-o e induzindo a uma transformação de seus conceitos. A questão ambiental gera, assim, um processo de intercâmbio e transposição de conceitos e métodos entre diferentes campos do conhecimento. Nesse processo vai se definindo o que é o ambiental de cada ciência centrada em seu objeto de conhecimento, problematizando-o e transformando-o, para internalizar esse saber ambiental que emerge nesse contexto. São esses corpos transformados de conhecimento que abrem espaço para a articulação interdisciplinar do saber ambiental.

O saber ambiental, aquilo que é externo a cada um dos paradigmas que configuram o sistema de conhecimentos da racionalidade econômica e tecnológica dominante, não constitui um discurso teórico homogêneo. O saber ambiental, entendido como uma constelação de conhecimentos que viabilizariam um desenvolvimento sustentável e suportável, democrático e equitativo, está em emergência. A reestruturação do saber, que demanda a transição para um desenvolvimento sustentável, não exige apenas uma integração interdisciplinar das ciências existentes. Para cada ciência e cada disciplina define-se um espaço do saber que transforma seus paradigmas no sentido de responder à demanda de conhecimentos que a problemática ambiental apresenta. Esses campos do saber ambiental vão se diferenciando em cada uma dessas disciplinas, em relação ao seu próprio objeto e campo de conhecimento, mostrando mais ou menos ductilidade para explicar e resolver os problemas ambientais.

O saber ambiental não emerge de um processo natural para a ecologização da sociedade, mas de uma luta ideológica e política pelo conhecimento, associada a uma luta pela reapropriação da natureza e cultura, pela autogestão dos processos produtivos e das condições de existência dos diferentes povos que configuram o gênero humano. Assim, pois, o saber ambiental é mobilizado por problemáticas socioambientais específicas, condicionadas pelo contexto econômico, ecológico e cultural em que se produzem, e por interesses sociais muitas vezes contrapostos. 
O saber ambiental não é gerado nem transformado a partir dos problemas internos do conhecimento, mas por um questionamento a uma racionalidade social que é transferida à ordem teórica. O campo do saber ambiental é configurado, assim, por certos saberes, técnicas e conhecimentos existentes, e pelo potencial de ambientalização das ciências através de um processo social que é externo e que as transforma, para constituir um sistema gnoseológico que serve de apoio à construção de uma racionalidade ambiental. (Leff, 1994b).

Assim, a própria ecologia gera conceitos referidos à forma de intervenção do homem (ou melhor, das formações sociais) na transformação das relações, funções e equilíbrios ecossistêmicos (conceitos de resiliência, capacidade de carga, taxas ecológicas de exploração de recursos); por sua parte, a antropologia ecológica e a ecologia cultural amalgamaram saberes sobre os processos de significação e as condições ecológicas do meio, os estilos étnicos e os desenvolvimentos técnicos, abrindo um diálogo entre a ordem material e simbólica de toda a organização cultural.

No campo da economia, cada escola define a seu modo o ambiente. Assim, a economia neoclássica dos recursos naturais procura internalizar as externalidades ambientais através do conceito de capital natural; a economia ecológica analisa as relações entre sistemas econômicos e sistemas ecológicos; a economia política do ambiente procura internalizar as condições ecológicas e comunais de uma produção equitativa e sustentável; e a ecologia política discute a questão da distribuição ecológica e a apropriação social da natureza.

Nessa perspectiva gnoseológica, o saber ambiental emerge em sua interação/integração/exclusão com os paradigmas do conhecimento estabelecido. A interdisciplinaridade ambiental não se refere, pois, à articulação das ciências existentes, à colaboração de especialistas portadores de diferentes disciplinas e à integração de recortes seletos da realidade, para o estudo dos sistemas socioambientais. Trata-se de um processo de reconstrução da racionalidade social através de uma reconstrução ambiental do conhecimento. É esta transformação dos paradigmas estabelecidos que permite que se abra a uma articulação teórica para dar conta da convergência de processos de diferente ordem conceitual, espacial e temporal, para apreender a complexidade de um sistema socioambiental concreto. Dir-se-á que finalmente a pobreza, o desmatamento e a erosão, assim como os índices de contaminação do ar, são observáveis na realidade. Sim, mas a perspectiva da qual se explicam as causas desses processos e se oferecem ações alternativas depende de estratégias conceituais que levam à reformulação de ideologias, valores, saberes, conhecimentos e paradigmas científicos que geram os dados observáveis da realidade.

Isso não significa que o campo do ambiental seja constituído só por teorias científicas e categorias abstratas. Todo saber ambiental inscreve-se num campo estratégico do conhecimento para a ação, referida à transformação da realidade econômica, política e social em que se enquadra a questão ambiental. E esse campo está habitado por um conjunto de saberes práticos, desde o saber estratégico no terreno da política e poder até os saberes técnicos aplicados à monitoração, ao diagnóstico, à avaliação e à prospecção dos processos ambientais e, principalmente, os sistemas tecnológicos e as técnicas que determinam o uso dos recursos naturais e as práticas de transformação produtiva. No campo do saber ambiental coexistem, pois, os valores, as técnicas e os conhecimentos teóricos. Assim, o uso efetivo e socialmente sancionado dos recursos depende tanto dos valores e saberes de cada cultura como da disponibilidade de conhecimentos e técnicas e das condições econômicas e políticas para sua aplicação. 
Isso torna necessário que seja definido o saber ambiental que já está sistematizado e que pode ser incorporado ao ensino superior, e, por outra parte, orientar a produção do conhecimento ambiental através de um processo de formação que integre a pesquisa e a docência num enfoque interdisciplinar. Isto implica em diversos problemas metodológicos para o desenvolvimento do conhecimento teórico, o formato de investigações participativas e de campo, e a realização de novas práticas docentes e pedagógicas para a transmissão dos valores e conhecimentos ambientais.

Neste sentido, a formação ambiental vai além do propósito de incorporar certos princípios gerais, métodos integrativos e técnicas específicas como componentes capazes de ambientalizar novos cursos e pós-graduações. O saber ambiental problematiza o desenvolvimento do conhecimento e discute a necessidade de legitimar e institucionalizar o saber ambiental, criando espaços para a pesquisa e a formação profissional nas universidades. Assim, a formação ambiental supõe novos desafios à educação superior na perspectiva do desenvolvimento sustentável.

\section{O processo de formação ambiental nas universidades}

Analisa-se como se torna complexo discutir a tarefa de gerar e incorporar na instituição universitária os valores e saberes ambientais, o que traz uma série de consequências para a elaboração curricular de cursos, cátedras, carreiras e pós-graduações ambientais. Isso explica, em parte, a dificuldade que as universidades enfrentaram para renovar os seus currículos e incorporar a dimensão ambiental aos seus programas de estudo. O saber ambiental não está incluído; muito menos acha-se repartido em elementos e componentes para serem incorporados pelas diferentes disciplinas existentes. Ao lado das resistências institucionais universitárias - principalmente nos tempos atuais de crise que as universidades latino-americanas atravessam - o saber ambiental enfrenta uma série de obstáculos epistemológicos que só serão vencidos por meio de uma produção teórica. No entanto, os saberes institucionalizados nas universidades geraram interesses disciplinares vinculados às práticas acadêmicas dominantes, que se opõem à sua transformação e à renovação das estruturas e aos conteúdos curriculares vigentes.

Esta resistência proveniente dos interesses interdisciplinares que encarnam na subjetividade do pesquisador e do professor universitário viu-se reforçada pela crise econômica que afetou a universidade - principalmente a universidade pública - em toda a região. Dessa maneira, os programas emergentes nas universidades surgiram mais da iniciativa de alguns indivíduos que do impulso e da planificação institucional para a formação ambiental. Isso gerou uma oferta dispersa e muitas vezes efêmera de programas de formação ambiental.

A formação ambiental implica na necessidade de gerar e sistematizar um saber ambiental que possa ser incorporado a novas estruturas curriculares e práticas acadêmicas capazes de formar um novo profissional com uma preparação mais abrangente de ordem teórica e prática para abordar os problemas ambientais de sua disciplina. Nos últimos anos, começaram a surgir projetos e programas de formação ambiental em temas relativos à gestão ambiental do desenvolvimento. Essas experiências não foram fáceis; por uma parte tiveram que vencer os obstáculos institucionais para abrir novos espaços acadêmicos para a produção de conhecimentos ambientais e a reformulação de programas de investigação e formação profissional; por outra 
parte, enfrentaram a dificuldade de integrar espaços acadêmicos rígidos para gerar uma formação de caráter interdisciplinar. Em muitos casos, os professores não reformularam seus conhecimentos, oferecendo um mosaico heterogêneo de conteúdos que os alunos nem sempre são capazes de integrar de maneira coerente em novas funções e práticas profissionais.

Isso deixa em aberto a questão de como viabilizar a incorporação da dimensão ambiental nas universidades. Para isso, é necessário concentrar esforços na formação de professores e pesquisadores, incluindo processos de autoformação e estratégias para elaborar conteúdos curriculares integrados. Um caminho para alcançar esse objetivo seria o estabelecimento de seminários permanentes de professores, nos quais se possa discutir tanto o avanço de novos métodos e conhecimentos ambientais como o aperfeiçoamento permanente da estrutura e dos conteúdos curriculares, bem como as práticas pedagógicas inovadoras. Da mesma forma, seria necessário identificar o saber ambiental existente para incorporá-lo ao currículo e buscar estratégias para gerar o saber ambiental faltante em diferentes disciplinas.

Já existe um saber ambiental plasmado no discurso do ecodesenvolvimento, da gestão ambiental e do desenvolvimento sustentável. Esse saber integra desde posturas epistemológicas, metodológicas, conceituais e ideológicas para o estudo de sistemas socioambientais até um conjunto de técnicas e métodos para o diagnóstico ambiental e estratégias para vincular o meio ambiente à perspectiva do desenvolvimento sustentável. Esse saber pode ser sistematizado em disciplinas, tanto obrigatórias como optativas, em todos cursos, com o qual iria gerando um interesse pela problemática ambiental em diferentes profissões. Mais do que isso, cada universidade poderia organizar cursos de formação sobre esse tema. Assim, professores de diversos cursos adquiririam esse saber geral e poderiam transformá-lo conforme as temáticas específicas de suas próprias disciplinas, elaborando cursos sobre as relações de cada uma delas com o desenvolvimento sustentável, que seriam dados nas faculdades e escolas de forma sistemática.

Por outra parte, existe um conjunto de saberes práticos e uma série de técnicas de avaliação e monitoração ambiental já sistematizados que podem ser incorporados a diferentes cursos, cátedras e carreiras. Refiro-me aos saberes técnicos especializados, como as técnicas de monitoração do ar, de análise e tratamento de água, de reciclagem de lixos, de sistemas de informação geográfica, incorporáveis aos cursos técnicos, bem como às metodologias de avaliação de impacto ambiental, que deveriam ser incorporadas aos cursos relacionados com todo o tipo de obras públicas e projetos de desenvolvimento. Também as aplicações das novas tecnologias à gestão ambiental (biotecnologia, microeletrônica, teledetecção e novos materiais) e o desenvolvimento de fontes alternativas de energia renováveis e não contaminantes deverão ser incorporados aos cursos tecnológicos.

Do mesmo modo, vêm se produzindo importantes avanços na ambientalização de diferentes disciplinas no campo das ciências sociais, que deveriam ser incorporados aos cursos existentes. Nesse sentido, a formação do antropólogo encontra uma enorme fonte de conhecimentos e saberes para o tratamento ambiental das relações entre as povoações humanas, a cultura e os recursos naturais, desde a ecologia cultural e a antropologia ecológica até o neofuncionalismo e o neoevolucionismo em antropologia, bem como todas as novas correntes de estudos etnobotânicos e etnotécnicos. Por sua parte, a economia ecológica tem desenvolvido novas abordagens, métodos e princípios para enfocar 
o problema das externalidades, a longo prazo, bem como a valorização dos recursos naturais e dos serviços ambientais (Martínez-Alier, 1995). Os cursos de direito poderiam incorporar já os avanços realizados em termos de direitos do cidadão ao ambiente e na legislação ambiental, tanto em nível internacional (protocolos, convenções, etc.) como em nível nacional. E a sociologia poderia aproximar-se dos conceitos de racionalidade ambiental, da análise dos movimentos ecologistas e dos interesses opostos que perpassam o campo ambiental pela apropriação da natureza.

Não se trata, naturalmente, de incorporar acriticamente os saberes ambientais que estão sendo produzidos, como o energetismo social, o biologismo na antropologia, ou as correntes neoclássicas em economia; pelo contrário, essas contribuições devem ser analisadas criticamente e no contexto da realidade natural e social de cada região e localidade, para gerar um saber capaz de avaliar e potencializar o patrimônio dos recursos naturais e culturais, incluindo neles os saberes ambientais como elementos fundamentais do potencial ambiental para um desenvolvimento alternativo. (Leff, 1994a).

Nesse contexto, as universidades devem realizar esforços para ir configurando os eixos temáticos que orientem o desenvolvimento do conhecimento e a produção de um saber ambiental capaz de transformar os paradigmas e disciplinas tradicionais. Este processo se dá através de um trabalho teórico e de pesquisa, do qual destacarei apenas dois aspectos fundamentais. Um deles é a necessidade de abrir espaço para a investigação interdisciplinar, orientada a problemáticas ambientais específicas, por meio de estudos de caso concretos. Isso permitirá desenvolver um saber sobre sistemas ambientais complexos, diagnosticando adequadamente os processos que determinam seu estado problemático atual, bem como elaborar programas alternativos de manejo ambiental. (García, 1986, 1994).

Por outra parte, as universidades devem se abrir para um processo de investigação participativa com as próprias comunidades e povoações em que ocorrem os problemas ambientais, captando os problemas nas bases e devolvendo-lhes o saber gerado para sua aplicação em programas e projetos de gestão ambiental. Isso supõe um vínculo necessário das universidades com os problemas ambientais de seu contexto, incorporando temas como o resgate de saberes autóctones e populares e seu melhoramento através da incorporação de conhecimentos tecnológicos modernos, bem como a transmissão do saber ambiental e sua assimilação por parte das comunidades, para potencializar suas forças produtivas e a capacidade de autogestão de seus recursos. Esses processos de investigação irão gerando novos conhecimentos teóricos, metodológicos e práticos que poderão ser sistematizados e distribuídos em novos conteúdos curriculares para a formação ambiental.

Por outra parte, a formação ambiental questiona os métodos tradicionais de ensino, apresentando novos desafios pedagógicos para a transmissão do saber ambiental, de um saber não só teórico, mas vinculado à prática, com uma estreita relação entre pesquisa, docência, difusão e extensão do saber. Dentro da sala de aula, por articular novos valores e orientações para a formação profissional, a formação ambiental demanda novos papéis para professores e alunos, novas relações sociais para a produção e a transformação do saber ambiental, novas formas de identificação e de inscrição das subjetividades nas práticas pedagógicas. $\mathrm{O}$ formato curricular não poderá elaborar seus conteúdos sem atender a esse processo social de geração do saber e da formação ambientais. 
As universidades desempenham um papel fundamental nesses processos de transformação do conhecimento vinculados à construção de uma racionalidade ambiental por sua responsabilidade social na formação de novos saberes e novos profissionais com uma consciência crítica e uma capacidade para contribuir com eficácia na resolução de problemas socioambientais cada vez mais complexos, para os quais as disciplinas tradicionais não oferecem respostas.

No entanto, não tem sido fácil para as universidades transitar de seus espaços de autonomia e de liberdade de pensamento para a transformação de suas estruturas e suas práticas acadêmicas, para responder ao desafio do desenvolvimento igualitário e sustentável; este induz a um processo de aumento da complexidade do saber que conduz à renovação das metodologias de pesquisa e das práticas de ensino, bem como à criação de novos profissionais com uma visão mais abrangente da realidade e mais conscientes e responsáveis de sua posição nela. A novidade dessa tarefa ambiental pressupõe a necessidade de produzir e aplicar novos conhecimentos e de incorporar a temática ambiental em cada universidade; de abrir novos espaços de cooperação entre faculdades e escolas e entre universidades e instituições de pesquisa.

As universidades da região estão iniciando importantes programas de cooperação e intercâmbio acadêmico em diversos campos da formação ambiental. No entanto, não é fácil passar da organização de seminários e programas conjuntos de extensão para a organização de verdadeiros programas de pesquisa e formação de caráter interuniversitário. Daí o desafio de induzir um processo de grande fôlego capaz de fortalecer as capacidades das universidades na temática ambiental através de programas cooperativos, de forma que se tornem protagonistas importantes das políticas ambientais de seus países e de seu contexto regional.
Os problemas ambientais globais ultrapassaram as fronteiras nacionais, exigindo a cooperação internacional para a sua solução. No campo do saber ambiental, essa cooperação torna-se ainda mais necessária, pelas capacidades incipientes de cada uma das universidades nas diferentes disciplinas ambientais, o que faz com que dificilmente cada universidade conte com massas críticas de pesquisadores e professores para desenvolver projetos consolidados de formação e pesquisa. A formação ambiental supõe, assim, a necessidade de estabelecer mecanismos para a cooperação interuniversitária e políticas transetoriais no plano da administração do desenvolvimento.

A questão ambiental coloca para a universidade a necessidade de se posicionar nas transformações sociais em direção ao desenvolvimento equitativo, democrático e sustentável. No entanto, a integração dos programas ambientais dos territórios onde estão localizados, ou da região como um todo, não se apresenta sem complicações. Isso se deve não só às dificuldades para financiar mecanismos eficazes de cooperação, mas também à própria resistência das universidades para transformar suas estruturas acadêmicas, bem como de cada um dos professores para incorporar métodos interdisciplinares na análise dos problemas ambientais emergentes, reorientar suas pesquisas e renovar os conteúdos de suas disciplinas e elaborar novas propostas curriculares.

Certamente o saber ambiental ultrapassa o espaço acadêmico das universidades: muitos saberes, métodos, técnicas estão sendo elaborados em outras instituições, tanto nas empresas de tecnologias ambientais como em novas estratégias produtivas que estão se formando nas organizações rurais e indígenas que lutam pela autogestão de seus recursos ambientais. Podemos afirmar que a filosofia ambiental, bem como a produção de muitas teorias e técnicas ambientais, também não estão emergindo 
das universidades, mas são produto do interesse individual de alguns intelectuais vinculados ao movimento teórico do ambientalismo. Isso é iniludível, dado o caráter do saber ambiental e a revolução dos valores, do conhecimento e das práticas sociais que este implica.

E, no entanto, a universidade não poderia nem deveria abandonar o papel fundamental que lhe cabe desempenhar nesse processo de transformações do conhecimento e de mudanças sociais. Ele requer um espaço legitimado de autonomia e liberdade de pensamento, bem como tempo de amadurecimento de conhecimentos, de elaboração de novas teorias, de sistematização e experimentação de novos métodos de pesquisa e de formação, que não são substituíveis pela capacitação técnica de curta duração, pela valorização mercantilista do saber nas empresas ou pela espontaneidade do ativismo ambientalista.
O processo de formação ambiental vai além da necessidade de estabelecer laços formais para complementar os programas ambientais existentes e orientar a tarefa universitária para a demanda de conhecimentos e a produção de profissionais que emergem dos problemas ambientais da região. $\mathrm{O}$ movimento ambientalista nas universidades implica em assumir com paixão e vocação a produção de um novo saber holístico e recuperar a função crítica e propositiva do conhecimento. Implica em gerar um saber eficaz e inventar utopias para conduzir novos processos sociais e produtivos que elevarão o homem aos ideais de igualdade, justiça e democracia, com novos conhecimentos, métodos e técnicas para a construção de uma nova racionalidade social, em que os valores e os potenciais da natureza, rejeitados pelo empenho produtivista da modernidade, orientem o renascimento da humanidade no novo século. 